\title{
Nova era \& ciberespaço \\ Ensaio prospectivo sobre suas afinidades eletivas \\ a partir de um estudo de caso
}

\begin{abstract}
New age and cyberspace
A prospective essay concerning their elective affinities - a case study

Airton Luiz Jungblut

Vitor Hugo da Silva Adami*
\end{abstract}

\begin{abstract}
Resumo: Busca-se neste artigo, de forma ensaística, indagar analiticamente sobre algumas afinidades eletivas que podem ser notadas entre ciberespaço e a religiosidade "new age". Como base para essa reflexão, foi analisado um evento religioso na Internet promovido pela celebre apresentadora de televisão e atriz norte-americana Oprah Winfrey, entre março e maio de 2008.
\end{abstract}

Palavras-chave: Ciberespaço; Religião contemporânea; Religião na internet

Abstract: From an essayistic approach, this article discusses analytically some elective affinities that can be observed between cyberspace and "the new age" religiosity. This reflection is based on a religious event on the Internet organized by the well-known North American actress and TV presenter Oprah Winfrey that took place from March till May 2008.

Keywords: Cyberspace; Contemporary religion; Religion and the internet

Religião e comunicação costumam andar juntas. A história da humanidade está repleta de exemplos dessa articulação, principalmente quando resulta bem sucedida. As grandes religiões que mais se disseminaram pelo planeta são casos exemplares a atestar os benefícios do uso de estratégias comunicativas na difusão de mensagens salvacionistas. Basta lembrar o sucesso que "religiões do

\footnotetext{
* A. Jungblut é doutor em Antropologia; professor e pesquisador no PPG em Ciências Sociais na Pucrs, Porto Alegre, Brasil. <jungblut@pucrs.br>. V. Adami é doutorando em Antropologia Social na Universitat Rovira i Virgili, em Tarragona, Barcelona, Espanha. <vitorhugoadami@, gmail.com>
}

\begin{tabular}{|l|l|l|l|l|l|}
\hline Civitas & Porto Alegre & v. 9 & n. 2 & p. 243-262 & maio-ago. 2009 \\
\hline
\end{tabular}


livro" como o judaísmo, o cristianismo e o islamismo tiveram. No cristianismo, impossível não lembrar também dos proveitos que o protestantismo soube tirar no século 16 da revolução gutemberguiana - fato que Lutero considerou "a maior graça de Deus" (Briggs e Burke, 2004, p. 38) - e também da expansão do pentecostalismo norte-americano através do televangelismo (rádio e televisão) no século 20 (Gurtwirth, 1998).

Nos dias atuais, quando assistimos aos meios de comunicação de massa (MCM) cederem espaço à comunicação mediada por computador (CMC), torna-se bastante pertinente indagar do uso que os grupos religiosos estão fazendo, principalmente, da Internet.

Análises realizadas por um dos autores deste texto (Jungblut, 2002 e 2008), dos usos que os grupos religiosos têm feito da internet no Brasil, apontam para uma utilização desajeitada e pouco eficiente dos recursos possibilitados pela internet, por parte de grupos religiosos institucionalizados e tradicionais, ao passo que é visível uma utilização mais eficiente desses recursos por parte de indivíduos autônomos, sejam eles vinculados ou não a grupos e tradições consolidadas. Até onde nos é possível verificar, essa é uma realidade internacional. $\mathrm{O}$ que se quer dizer com isso é que o uso religioso eficiente da internet tem sido mundialmente muito mais individual do que institucional. Mais do que isso, se desconfia que essa mídia não se presta a "grandes eventos" religiosos que congreguem, apesar das facilidades tecnológicas favoráveis, um número elevado de participantes simultâneos. Por essa razão, não se prestando a realizar aquilo que Durkheim considerava de fundamental para a existência da religião: o culto público que permite a sociedade sentir seus efeitos quando indivíduos que a compõem estão reunidos e agem em comum (Durkheim, 1989, p. 495). Até há alguns meses atrás, não se tinha notícia de nenhum evento religioso na internet de grande procura e repercussão que pudéssemos enquadrar nessa categoria. Esse quadro se altera com um episódio que pretendemos analisar neste artigo. Analisando-o, pretendemos problematizar algumas das lógicas que orientam a eficácia do uso da comunicação mediada por computador para fins religiosos. Vejamos, então, o episódio.

\section{Oprah Winfrey e Eckhart Tolle}

Por dez segundas-feiras, de março a maio de 2008, no programa da apresentadora norte-americana Oprah Winfrey, no site oprah.com, foi possível assistir e participar da discussão online do livro $A$ new earth: awakening to your life's purpose do best-seller e conselheiro espiritual Eckhart Tolle. 
Este evento, sob o formato de aulas - A new earth online class - congregou, simultaneamente, pessoas oriundas de mais de 139 países para o primeiro dia de aula. ${ }^{1}$ Mas quem são esses personagens e qual a razão de seu inusitado sucesso na web?

Oprah Gail Winfrey nasceu em 1954 no Mississipi, Estados Unidos. Ela é considerada por muitos norte-americanos como um verdadeiro mito de audiência. Em 2005, foi eleita pela revista Forbes como "a mulher mais poderosa". A revista Life a posicionou como "a mulher mais influente de sua geração" do ano e a revista Time a denominou como uma das quatro pessoas que "deu forma" ao século 20 e início do século 21. Em 2005, a revista Business Week a classificou como a maior filantropa da raça negra na história dos Estados Unidos. Trata-se de uma "estrela" da televisão que ganha cerca de 260 milhões de dólares por ano. Oprah, contudo, não é somente uma popular apresentadora de televisão. Seu enorme êxito neste meio the assegurou levar adiante uma série de outras atividades. Possui uma produtora, Harpo Entertainment Group, já escreveu livros, dirige seu próprio website e, inclusive, é a editora de The Oprah Magazine, uma revista que segue a mesma linha do seu The Oprah Winfrey Show, que é o talk-show número um de audiência das televisões norte-americanas. Aproximadamente 30 milhões de expectadores assistem a seus programas somente nos Estados Unidos.

Aliada a sua fama de um ícone de audiência americana ela também vem sendo reconhecida como uma "líder espiritual". Um artigo de 2002 da revista Christianity Today insinua que Oprah tenha fundado uma igreja: "The Church of $O$ ". Um fragmento a respeito dessa notícia informa o seguinte:

Since 1994, when she abandoned traditional talk-show fare for more edifying content, and 1998, when she began 'Change Your Life TV', Oprah's most significant role has become that of spiritual leader. To her audience of more than 22 million mostly female viewers, she has become a postmodern priestess - an icon of church-free spirituality. (Taylor, 2002)

Por estas e outras razões ela tem sido considerada pertencente ao movimento New Age. Oprah vem negando esse vínculo com a New Age e tem se declarado uma fervorosa seguidora dos ensinamentos de Jesus Cristo. Mesmo assim, o pastor da primeira Igreja Batista em Arkansas, John Hamby, em um de seus sermões, ${ }^{2}$ abordou fatos sobre a sua questionável postura na

1 Ver: http://www.oprah.com/package/oprahsbookclub/anewearth/pkganewearthwebcast/ 20080130_obc_webcast_anewearth Conforme dados do programa: oprah.com, chapter 1, transcript.

2 Ver: http://www.sermoncentral.com/sermon.asp?SermonID=121020. Acesso em 8 out. 2008. 
mídia como uma cristã. Ele ressaltou que o próprio pastor da igreja que ela diz frequentar, a Trinity United Church of Christ em Chicago, a mesma em que Barack Obama é membro, fez comentários a respeito de suas posturas "anticristãs". Segundo a declaração do pastor da Trinity United Church:

She has broken with the traditional faith, she now has this sort of God is everywhere, God is in me, I don't need to go to church, I don't need to be a part of a body of believers, I can mediate, I can do positive thinking' spirituality. It's a strange gospel. It has nothing to do with the church Jesus Christ founded! ${ }^{3}$

Mesmo sofrendo esse enérgico "patrulhamento" evangélico, a disposição de Oprah em procurar midiatizar uma "espiritualidade livre" não tem arrefecido em seus programas. Como exemplo, pode-se relatar o seu programa na Radio XM, onde Oprah frequentemente abre espaço para figuras como Marianne Williamson, uma feminista americana que apresenta diariamente fragmentos e comentários sobre o livro A course in miracles. Esse livro teria sido psicografado por Helen Schucman, uma falecida professora de Psicologia da Universidade de Colúmbia, em Nova Iorque, que dizia, ao longo dos anos sessenta, "canalizar" os "ensinamentos complementares de Jesus Cristo". 4 Em seu site também há o Soul series, um programa onde Oprah entrevista distintas pessoas que escrevem livros e procuram ter um estilo de vida em que se busca o "desenvolvimento pessoal e novas espiritualidades". Paralelamente, há, ainda, o "Oprah book club", que é o seu clube de livros preferidos. Um dos livros eleitos para apreciação em seu clube foi o do "conselheiro espiritual" Eckhart Tolle: A new earth: awakening to your life's purpose. Foi a partir desse seu profundo interesse por esse livro que ela ousou montar um "webinar", disponibilizando em seu site um "seminário global" de quase 2 horas, ao vivo, por 10 semanas. Um dos propósitos do evento era propiciar aos interessados uma maior compreensão do que seria "o despertar para um novo mundo agora", segundo Eckhart Tolle.

Ulrich Tolle, por sua vez, mais conhecido como Eckhart Tolle, ${ }^{5}$ nasceu na Alemanha. Entre seus 13 e 19 anos de idade, de 1961 a 1967, viveu com seu pai na Espanha. Depois desse período foi morar na Inglaterra. Ele não frequentou uma escola formal entre as idades de 13 a 22 anos. Recusava-se a isso por considerá-las "ambientes hostis", mas mantinha autodidaticamente estudos de "interesse pessoal". Mesmo com a repulsa a uma educação formal,

\footnotetext{
3 Ver: http://www.sermoncentral.com/sermon.asp?SermonID=121020. Acesso em 8 out. 2008

4 Ver: http://www.grupoelron.org/quienes/cursodemilagros.htm. Acesso em 9 out. 2008.

5 Em uma das aulas, Oprah chamou Eckart Tolle como "the father of Now".
} 
graduou-se posteriormente pela University of London e completou sua pesquisa na Cambridge University. Estudou literatura, línguas e filosofia.

Segundo sua própria narrativa (Tolle, 1999), ele teria, aos 29 anos, passado por uma transformação radical em sua vida. Durante uma crise suicida, ele diz que "se ouviu", quando ele repetia para ele mesmo que "não suportava mais viver com ele". Neste instante, ele se deu conta que havia duas pessoas em si: uma que escutava e a outra que reagia. Dar-se conta de uma segunda pessoa, a testemunha de si mesmo, foi para Tolle o desencadear de sua "outra visão de mundo". Os anos seguintes a essa crise foram destinados a estruturar e aprofundar essa transformação em sua vida. Depois de certo tempo, Tolle começou a trabalhar em Londres como conselheiro espiritual de pequenos grupos e, também, dando consultas individuais.

Um outro "ímpeto de consciência" o levou a mudar da Inglaterra para o Canadá, sem um motivo aparente e lógico que justificasse tal mudança. Foi entre a Califórnia e Vancouver que, segundo sua narrativa, ele conseguiu reunir a "atmosfera" e a devida inspiração para escrever seu primeiro best-seller $-O$ poder do agora. Esse livro foi traduzido para 33 idiomas e foi considerado pelo New York Times o primeiro livro de um autor mais vendido nos EUA. ${ }^{6} \mathrm{O}$ poder do agora tem como propósito central ensinar o "estado de consciência de estar alerta (consciente) para o momento presente", "a presença", ou seja, "observar a realidade como ela se apresenta por si só".

O seu best-seller mais recente é $A$ new earth. Nesse livro, Tolle (2007) procura explorar a "estrutura do ego humano". Faz uma série de questionamentos e se propõe, como objetivo do livro, respondê-los. As seguintes perguntas foram ressaltadas:

¿Está preparada la humanidad para una transformación de la conciencia, un florecimiento interior tan radical y profundo que, comparado con él, la floración de las plantas, por mucha que sea su belleza, es solo un pálido reflejo? ¿Pueden los seres humanos perder la densidad de sus estructuras mentales condicionadas y llegar a ser como cristales o piedras preciosas, transparentes a la luz de la conciencia, por así decirlo? ¿Pueden oponerse al tirón gravitatorio del materialismo y la materialidad y elevarse por encima de la identificación con la forma, que sujeta al ego y los condena a ser prisioneros dentro de su propia personalidad? (Tolle, 2007, p. 16-17).

Tolle (2007, p. 17) enfatiza que o seu ensinamento sobre a "transformação da consciência humana" é uma mensagem retórica advinda dos ensinamentos

\footnotetext{
6 http://www.eckharttolle.com/eckharttolle-about. Acesso em 7 out. 2008.
} 
centrais dos grandes sábios da humanidade como, por exemplo, Jesus, Buda e outros.

Na visão de Tolle (2007, p. 18), a "tomada de consciência" para a grande maioria das pessoas não é um evento singular, mas um processo. Uma gradual (des)identificação dos pensamentos e emoções. O autor adverte, contudo, que nem todas as pessoas do planeta estão preparadas para esse "despertar", mesmo reconhecendo que é uma faculdade acessível a todos os seres humanos. Ao mesmo tempo, Tolle afirma que já existe um significativo número de "indivíduos despertos". Por sua vez, esses deverão desencadear o processo de aceleração para o estabelecimento de uma "consciência coletiva desperta" o mais abrangente possível.

A união de Eckhart Tolle aos empreendimentos de Oprah no ciberespaço ("um mito de audiência") não poderia estar mais sintonizado com o seu propósito de obter um possível "despertar global". E essa modalidade de evento - "webinar" - tornou possível reunir, simultaneamente, para a primeira sessão, como já dito, um público de aproximadamente dois milhões de pessoas oriundas de diversas partes do mundo. ${ }^{7}$

\section{A World wide web market de Oprah Winfrey e Eckhart Tolle}

Após o preenchimento de um pequeno cadastro no site da Oprah.com se gerava um login de acesso para a página do evento. Uma semana antes do "primeiro dia de aula", 3 de março de 2008, já era possível acessar a página, onde já havia um link de "entrada para sala de aula" e um cronômetro marcando o tempo regressivo para o início das aulas. Havia, também, um teste prévio para verificar se você tinha o programa de vídeo compatível para a transmissão. Caso contrário, já estava disponível o seu download gratuito. O horário estabelecido para iniciar foi às oito da noite, num dos fusos horários dos Estados Unidos. Na data prevista, procurou-se ficar atento ao cronômetro para que no momento exato que esse fosse zerado se pudesse clicar e, assim, "buscar um lugar" rapidamente. Conforme aviso prévio, corria-se o risco de um "congestionamento no espaço virtual". A conexão no "primeiro dia de aula" foi lenta e com muitas interrupções. Para as outras aulas o problema foi solucionado.

As "portas foram abertas" com trinta minutos de antecedência, com uma música "estilo new age" no fundo. Paisagens de montanhas, do amanhecer, de

7 Ver: http://www.sermoncentral.com/sermon.asp?SermonID=121020\&Page=2. Acesso em 8 out. 2008. 
gente bonita sorrindo, de flores, crianças, enfim imagens que estimulavam uma sensação de bem-estar e harmonia foram exibidas. Em um segundo momento, apareceram depoimentos de gente famosa, de pessoas da platéia do programa "Oprah Show", falando dos insights e das mudanças que aconteceram em suas vidas depois que leram o livro de Tolle. Cabe ressaltar que as primeiras cenas de abertura foram de propagandas dos patrocinadores: Chevy, Post-it e Skype. O contato do público com o evento poderia ser feito por email, telefone ou via Skype.

Num dado momento cessaram as propagandas e surgiu a imagem da Oprah com ar de seriedade, mas, também, de entusiasmo. As suas primeiras palavras foram:

Welcome to our very first live world wide interactive event. We are here tonight breaking new ground. Nothing like this has ever been attempted before. Right now you all are online with me from every corner on our planet. Places like Albania, Bolivia, Cambodia, Ecuador, Finland, Hong Kong, China, India, Zimbabwe, Australia, Canada, the U. K., and the rest of Europe. Along with, of course, all 50 states here in our United States of America. Over 139 countries are represented in our class tonight. Welcome to you all. ${ }^{8}$

\section{A religiosidade cristã de Oprah}

A primeira pergunta, via Skype, foi de uma mãe de família de Illinois, Estados Unidos, que questionou a fé cristã de Oprah. Kelly perguntou:

I had a Catholic upbringing, I married a Catholic, and we're raising our children this way. In reading books such as Tolle's, I've really, it's really opened my eyes up to a new way of thinking; a new form of spirituality that doesn't always align with the teachings of Christianity. So my question is to you, Oprah, how have you reconciled these spiritual teachings with your Christian beliefs? ${ }^{9}$

Oprah, inicialmente, se surpreendeu que a primeira pergunta fosse dirigida a ela. Procurou respondê-la contextualizando e justificando-se com fatos de sua trajetória como membro da Igreja Batista durante vinte anos. Comentou que teria que estar na igreja às oito da manhã para, assim, conseguir

\footnotetext{
8 Ver: http://www.oprah.com/package/oprahsbookclub/anewearth/pkganewearthwebcast/ 20080130_obc_webcast_anewearth. Conforme dados do programa: oprah.com, chapter 1, transcript.

9 Utiliza-se os nomes reais das pessoas, conforme transcrição da primeira aula. http://www.oprah. com/package/oprahsbookclub/anewearth/pkganewearthwebcast/20080130_obc_webcast_ anewearth - Chapter 1
} 
um lugar para sentar e assistir a um sermão de um pastor carismático. Numa dessas idas à igreja se surpreendeu quando ouviu o pastor dizer que "Deus era onipotente, onipresente, onisciente, que Deus era tudo e que Deus era ciumento." Quando escutou isso, disse que ficou chocada com o comentário do pastor ao refletir na possibilidade de "Deus ter ciúmes dela".

Para Oprah, essa incoerência ouvida do pastor, em dizer que "Deus pode ser tudo e pode ter ciúmes", fez com que ela repensasse sua postura diante da igreja. Decidiu, então, procurar se "relacionar com Deus" a partir de uma maneira menos condicionada as normas e as doutrinas religiosas.

O complemento da resposta à interlocutora sobre o seu processo de reconciliação com os ensinamentos de Jesus Cristo na sua vida pessoal foi baseado na citação de outro livro de sua preferência. Segundo Oprah:

There's another book by a woman named Elizabeth Lesser, it's called, "The Seeker's Guide," where she talks about the new spirituality versus the old. So I just wanted to - this is on page 51 and 52 of Elizabeth Lesser's book called "The Seeker's Guide." And she talks about old spirituality versus the new spirituality and she says the old was - the old way is the hierarchy has the authority. Church authorities tell you how to worship in church and how to behave outside of church. The new spirituality is that you are your own best authority as you work to know and love your self, you discover how to live a more spiritual life. ${ }^{10}$

Eckhart Tolle fez uma complementação para a resposta de Oprah procurando conciliar religião e espiritualidade dizendo que isto é possível desde que se consiga "ultrapassar a experiência da religião para uma experiência mais profunda da fé". Segundo Tolle:

Well, religion can be an open doorway into spirituality and religion can be a closed door. It prevents you from going deeper. So that I love reading the New Testament and I also read the Old Testament. Sometimes there's some incredible jewels in there. (...) And I started reading and I immediately recognized the deep truths that is there and I realized the truth that is deeper, that is expressed in what Jesus said is much deeper than what you, how the church interprets it. There's a depth to it. And it reflects your own depth when you read it. So there's no conflict between this teaching, which is purely spiritual, and any religion. Because if you go deep enough in your religion, then you all get to the same place. It's a question of going deeper so there's no conflict here. ${ }^{11}$

${ }_{10}$ Ver citação no transcript: http://www.oprah.com/package/oprahsbookclub/anewearth/ pkganewearthwebcast/20080130_obc_webcast_anewearth - Chapter 1

11 Ver citação no transcript: http://www.oprah.com/package/oprahsbookclub/anewearth/ pkganewearthwebcast/20080130_obc_webcast_anewearth - Chapter 1 
Oprah sugeriu na sua resposta a vivência da espiritualidade a partir de uma via menos institucionalizada. Ela não negou os ensinamentos de Cristo, mas reconheceu a partir da sua experiência pessoal na Igreja Batista o quanto o rigor doutrinário e normativo de uma instituição religiosa tradicional pode coibir a vivência dos ensinamentos de Jesus. Por sua vez, Tolle reconheceu que a religião pode ser uma porta para a espiritualidade, desde que se procure aprofundar a doutrina religiosa na experiência da vida pessoal.

Observou-se, contudo, que ambos os discursos remetem para a adoção de postura individualista de consumo personalizado de bens religiosos, do tipo: "faça você mesmo". Essa postura pressupõe ainda atitudes desinstitucionalizantes, destradicionalizantes e desteologizantes muito próprias de um jeito "pós-moderno" de se servir de religiões e religiosidades.

$\mathrm{O}$ que de fato ocorreu depois desta primeira web class foi uma explosão de comentários sobre os pronunciamentos de Oprah e Tolle diante da fé cristã. Algumas repercussões foram notadas no ciberespaço. De acordo com o pastor da primeira Igreja Batista em Arkansas, John Hamby:

This is cause for concern in that she is using her fame and influence to promote a false religion which will ultimately lead those who follow it to destruction. Equally of concern is that many of her followers are Christians who are confused and even seduced by this empty philosophy. ${ }^{12}$

O pastor Frank Mazzapica da New Convenant Church of Houston gravou um vídeo no YouTube ${ }^{13}$ fazendo uma advertência a Oprah. O vídeo deixa bem explícita a insatisfação da sua igreja diante do que foi comentado a respeito de religião e espiritualidade no "primeiro dia de aula". Como Oprah é milionária, líder de audiência e realiza muitas obras assistenciais a populações carentes, o pastor reconheceu com estima sua "obra cristã". Todavia, fez uma advertência mencionando que ela estaria sendo persuadida, iludida por uma tendência enganosa de falsa espiritualidade. Por isso, ele mesmo, em nome da igreja, pediu que ela parasse de veicular em seus programas mensagens que pudessem abalar a fé cristã.

12 Ver: http://www.sermoncentral.com/sermon.asp?SermonID=121020\&Page=2. Acesso em 8 out. 2008.

${ }^{13}$ Ver vídeo: http://es.youtube.com/watch?v=NMy7fPRoTAI - vídeo: A warning for Oprah. Acesso em 8 out. 2008. 


\section{Oprah, Tolle e as características atuais da religiosidade norte-americana}

A forma como ocorre essa associação entre Oprah e Tolle é representativa de processos de desinstitucionalização religiosa muito recorrentes na história dos EUA desde pelo menos o fim do século 19. Pode-se observar, por exemplo, uma grande semelhança entre esse caso e aquele vivido pela dupla Phineas Quimby e Mary Baker Eddy (Jungblut, 2006). Phineas Quimby foi o principal expoente de um movimento chamado "Novo Pensamento", que também está na gênese do "pensamento positivo" e da "autoajuda". Esse movimento, ocorrido em meados do século passado nos EUA e que mormente é qualificado de "metafísico", abrigando pesquisas nos campos do ocultismo, espiritismo, hipnose, parapsicologia, etc., postulava, entre outras coisas, que "o homem pode criar sua própria realidade através do poder da afirmação positiva" (Hanegraaff, 1996, p. 31). Tais ensinamentos "metafísicos" de Quimby teriam influenciado profundamente uma jovem senhora evangélica de nome Mary Baker, posteriormente Mary Baker Eddy, que, bastante interessada no poder da mente mas também muito ligada aos ensinamentos cristãos-evangélicos, acabou por desenvolver a partir de pesquisas e escritos uma versão indisfarçavelmente gnóstica de cristianismo e fundar uma organização religiosa chamada "Ciência Cristã" para a difusão de suas ideias e a prática de curas através da mente. Segundo Mary Eddy, em livro intitulado Ciência e saúde com a chave das escrituras (uma espécie de Bíblia para os "cientistas cristãos"), "a realidade da Mente mostra de modo concludente como é que a matéria parece existir, mas não existe" (Eddy, 1995, p. 123).

Casos como esse, e outros que poderiam ser citados, e a recente associação entre Oprah e Tolle ilustram algo que já começa a ser notado nos EUA: um processo visível de destradicionalização e desinstitucionalização das experiências religiosas e que, na maioria das vezes, tem conduzido a movimentos religiosos indisfarçavelmente gnósticos. Tem-se aqui, portanto, uma porta de entrada importante para se compreender algumas das características assumidas pela religiosidade norte-americana nas últimas décadas.

Segundo Harold Bloom, em um interessante ensaio que trata das características contemporâneas da religião norte-americana, o gnosticismo estaria, na atualidade, entranhado no interior de praticamente todas as formas de religião norte-americanas sem que isso seja visível para a maioria. Eis o quadro que o autor descreve: 
gnosticismos autênticos acham-se espalhados onde quer que nossos caudilhos republicanos sulistas ou do Oeste façam culto [...] e onde mais que espiras de templos mormons e Primeiras Igrejas Batistas perfurem os céus. Nossa Religião Americana, de fabricação caseira ou ostensivamente católica romana e protestante dominante, é mais um amalgama gnóstico que um tipo europeu de cristianismo histórico e doutrinal, embora muito poucos possam ver isso, ou talvez a maioria não queira ver. Alguns assustados padres católicos [...] tomaram consciência de seu perigo, e um punhado de ministros protestantes agora compreende que sua neo-ortodoxia está cedendo a um neognosticismo populista. Mas as grandes manifestações transcendem as igrejas, e são muito maiores até que as legiões de companheiros de viagem da Nova Era. Nossas indústrias em desenfreado florescimento de culto aos anjos, "experiências de quase morte" e astrologia - redes de adivinhação de sonhos - são versões em massa de um gnosticismo adulterado ou travestido (Bloom, 1996, p. 32).

A situação que Bloom descreve parece não se restringir exclusivamente ao campo religioso norte-americano pois é possível ver um quadro semelhante sendo detectado por alguns observadores do universo religioso contemporâneo em nível mundial (Campbell, 1997). O que, como se vê, emerge de maneira dramática nesse processo em que, de diferentes formas, princípios difusos de gnosticismo se disseminam por todos os lados, é a situação de fragilidade em que se vêem as tradições religiosas mais ortodoxas, as tradições mais resistentes ao sincretismo. A disseminação da gnose, de uma religião imanentista, ou de uma "teodicéia oriental" - termos que, em essência, nomeiam uma mesma tendência que se vive hoje de busca, nas mais diversas tradições religiosas, de uma receita para a "autodeificação" - não se faz sem que as tradições religiosas mais consolidadas e estáveis sejam assediadas e sofram, muitas vezes, reformulações consideráveis, e isso ocorre tanto para o júbilo dos que assim o desejam como para o desespero daqueles que vêem princípios, dogmas, confissões, etc. de sua fé sendo relativizados, emendados por novas profecias atualizantes, ou, simplesmente, ajustados aos imperativos do "mercado".

Para nomear esse processo tem sido empregado, de um modo geral, o termo destradicionalização (Velho, 1997; Fry, 1998; D’Andrea, 1996). Ele designa qualquer situação onde houve ou há um processo de declínio da tradição, religiosa ou não, como norteadora do comportamento dos indivíduos ou dos grupos sociais. Mas, também tem havido o emprego de outros neologismos para tratar de aspectos mais precisos desse processo e que atingem especificamente as tradições religiosas, como, por exemplo, "nova-erização", criado por Anthony D'Andrea para nomear aqueles processos destradicionalizantes da 
religião que resultam para os grupos ou indivíduos neles envolvidos na adoção de práticas e cosmovisões afins com o que genericamente se conhece por “Movimento Nova Era" ou "New Age". Segundo D'Andrea:

Um sistema ou grupo é New Age, ou se transforma em New Age, se sofrer um processo de "nova-erização", ou seja, se incorporar, ou suscitar nos indivíduos, formas individualizantes (místicas, inner-directed) $e$ reflexivistas (destradicionalizantes, contingencializantes e praxiológicas) (D’Andrea, 1996, p. 65).

A "nova-erização", segundo esse autor, atingiria até mesmo as religiões tradicionais num processo que favorece a autonomia individual na mesma proporção em que tende a tornar desnecessárias as organizações especializadas na manutenção e perpetuação das tradições religiosas:

[...] tomando-se a reflexividade institucional da modernidade (e o "individualismo reflexivo") enquanto processo condicionante (ainda que não determinante), é de se esperar que as grandes religiões, especialmente as ocidentais, se reflexivizem (isto é, se 'novaerizem'), assumindo formas de religiosidade destradicionalizadas, individualizadas e individualizantes, que tendem a se autonomizar de organizações eclesiais (D'Andrea, 1996, p. 307).

O que fica evidente desses processos atuais pelo qual passa a religião norteamericana, seja qual for o termo empregado para nomeá-los e independente dos aspectos eleitos como fundamentais para compreendê-los, são os ganhos na esfera da autonomia individual, do poder individual. Isso ocorre, em parte, como fruto das modificações na forma como passa a ser concebida a relação homem-Deus (imanentismo, quebra da dualidade homem-Deus, gnose, etc.), o que leva o indivíduo a conceber-se, através de exercícios subjetivos e internalizados, como detentor de uma divindade que não é mais exclusiva de um único Deus separado deste mundo. Essa pretensão ou esse exercício de "autodeificação" que, pode-se dizer, não deixa de ser narcísico, certamente induz o indivíduo a um agir mais audacioso no mundo, pois tenderá ele a considerar sua vontade, já que divina, como imperiosa diante da realidade. Em outras palavras, dota-o de uma confiança psicológica diante do mundo, dota-o de um poder interno de autossugestão que efetivamente tem validade num mundo onde atribui-se positividade ao autocontrole, à autoconfiança, à autoestima, à coragem para a iniciativa audaciosa, à impetuosidade empresarial, etc..

Em segundo lugar, a situação em que se encontra religião atual gera ganho de poder ou autonomia para os indivíduos nela envolvidos pela verificada perda de importância atribuída ao papel das tradições religiosas 
decorrentes de fenômenos tais como o surgimento do pluralismo religioso e a consequente instauração de uma lógica de mercado religioso, o surgimento do espontaneísmo, da "desteologização", do reflexivismo individual, etc., mas também pelo enfraquecimento da capacidade congregacional e ético-coercitiva das comunidades religiosas tradicionais.

Há que se falar ainda de um poder obtido pelo indivíduo frente à religião que, embora esteja, em parte, implicado no processo geral de destradicionalização religiosa, merece aqui algumas considerações já que se trata de um aspecto importante dessa autonomia individual de que se está falando. Trata-se do poder adquirido pelos indivíduos de comporem seus próprios sistemas religiosos de acordo com suas necessidades e preferências pessoais. Para melhor ilustrar esse tipo de autonomia é apropriado utilizar aqui uma caracterização feita por Pierre Sanchis do que ele considera "pósmoderno" em algumas formas de experiências religiosas da atualidade. Diz o autor:

Pós-moderno: uma construção eclética mais ainda do que um verdadeiro sincretismo, que recorta os universos simbólicos - o do seu grupo e os alheios, todos igualmente "virtuais" - e multiplica as "colagens", ao sabor de uma criatividade idiossincrática ("idiossincrética"...), radicalmente individual, mesmo se se articula em tribos de livre escolha (Sanchis, 1997, p. 104-105).

Sanchis é muito feliz ao sugerir o termo "idiossincrética" para definir esse tipo de colagem criativa "radicalmente individual" que caracteriza muitas das atuais atitudes dos indivíduos frente às tradições religiosas. O termo, ao nomear um tipo de produção idiossincrática de sincretismos religiosos, dá conta do que, efetivamente, se verifica em muitas formas de experiências religiosas da atualidade. Nomeia com perspicácia não somente uma atitude normal nos dias de hoje de consumo diversificado e eclético de bens religiosos, que é característica de uma situação de mercado religioso (atitude que vale-se de relativizações pragmáticas, tais como: "todos os caminhos levam a Deus"), como também, de forma mais evidente, o tipo de crenças características do que se chama de "Movimento Nova Era". Essas, como demonstra D'Andrea, ao serem produzidas e atualizadas por um ativo "reflexivismo individual", têm, quase que exclusivamente, no compósito produzido pelo indivíduo a única e efetiva - se é que se pode chamar assim - unidade doutrinal verificável e, mesmo assim, sempre de uma forma aberta e provisória. A atitude "idiossincrética", sintetiza de certa forma uma manifestação extremada de autonomia individual ligada à destradicionalização religiosa pois com ela já não se trata nem mais de escolher a que tradição religiosa se filiar e como permitir que ela interfira 
na vida do indivíduo e sim de escolher quais elementos de uma ou de mais tradições são válidos e úteis para o indivíduo e se harmonizam com sua personalidade ou temperamento religioso. Nesse processo as tradições tendem a não ser percebidas pelos indivíduos como unidades indecomponíveis mas, sim, como espécies de depósitos de onde é possível retirar "peças" sem que se precise levar tudo, o "kit" completo. Com a possibilidade de fazer uso de um idiossincretismo, o indivíduo, então, investe-se de uma autonomia frente às tradições religiosas análoga a que se utiliza para, por exemplo, escolher os itens que se quer ter disponíveis num carro ou computador que se pretenda comprar.

Como já se fez menção a áreas da religião tradicional que sofrem um processo de "nova-erização", a atitude "idiossincrética" começa a ser experimentada também ali, onde a tradição sempre tendeu a se manter integral e ser relembrada, com alguma disciplina doutrinal, a partir de consensos coletivamente instituídos. Mas esse processo não ocorre livre de tensões, como atesta, por exemplo, o "patrulhamento" evangélico sofrido por Oprah.

Em síntese, o que se pode observar disso tudo é que a religiosidade que Oprah busca desenvolver em sua associação com Tolle possui todos os elementos característicos desta religião pós-moderna e "nova-erizada" em desenvolvimento nos EUA. Oprah, indiscutivelmente, encena um movimento destradicionalizante quando (a semelhança do movimento de Mary Baker Eddy em direção a Phineas Quimby) minimiza a necessidade de se manter fiel à ortodoxia protestante em proveito dos ensinamentos gnósticos como aqueles que são fornecidos por Tolle. Ao fazê-lo, adota uma atitude reflexivista e idiossincrética de lidar com suas necessidades de consumidora de religiosidade. Além disso, insere-se num circuito desinstitucionalizado de debates povoado por pessoas que procuram o "desenvolvimento pessoal e novas espiritualidades". E é a internet que passa a fornecer a melhor ambiência para essas atividades interlocutórias. Vejamos como isso ocorre.

\section{Algumas das lógicas do ciberespaço que devem ser lembradas aqui}

Nos últimos anos, têm-se acumulado uma série de diagnósticos sociológicos e antropológicos a respeito das lógicas culturais, sociais e comunicacionais que imperam neste ambiente denominado ciberespaço surgido através da emergente comunicação mediada por computador. Alguns destes diagnósticos, de lembrança oportuna para a análise aqui pretendida, apontam para o fato de que o ciberespaço tornou-se um território livre para 
manifestações, com uma radicalidade nunca antes experimentada, de todas as alteridades existentes no mundo globalizado; um espaço em que qualquer pessoa dotada de um mínimo de recursos consegue disponibilizar a centenas de milhões de pessoas informações que considera relevantes a qualquer causa ou finalidade. Isso ocorre devido ao fato de que todo o indivíduo na internet tem o poder de se transformar facilmente em publicador eficiente de textos seus ou de outras pessoas. Para alguns analistas, isso torna finalmente realizável uma antiga ambição das democracias modernas de tornar todo indivíduo efetivamente livre para manifestar suas ideias, seja lá quais forem. Essa característica do ciberespaço deve-se ao fato de que, ao contrário dos meios de comunicação de massa, que possuem uma arquitetura unidirecional um-para-muitos (um emissor - muitos receptores), a comunicação mediada por computador possui uma arquitetura preponderantemente bidirecional muitos-para-muitos (quase sempre todos são, simultaneamente, emissores e receptores). A consequências mais notável disso, conforme observa W. Daniel Hillis, é o surgimento de uma energética e democratizante polifonia comunicacional:

[...] ao contrário do que acontece nos meios de transmissão [meios de comunicação de massa], talvez haja mais bocas do que orelhas na Internet. Isso é possível porque a Internet reduz o limiar de publicação, o limiar de extração de informações. As pessoas desconfiam das instituições. Não gostam de ter sua voz limitada pelas instituições. A ideia de que podem ter o poder nas próprias mãos e divulgar algo na Net se adapta ao clima desses tempos, que exige autoconfiança. A energia da Web não vem das pessoas que estão buscando informações. Vem das pessoas que têm informações que desejam enviar ou que oferecem mecanismos para fornecer essas informações a outras pessoas (Hillis, 1997, p. 109).

Por ser, então, o ciberespaço um território tão favorecedor desta polifonia democratizante de que se fala, há, também, quem o perceba como recurso tecnológico a serviço das intensas reflexividades identitárias que seriam experimentadas pelo indivíduo contemporâneo. Verdadeira "tecnologia do eu", o ciberespaço, ao disponibilizar uma interminável fonte de material de confrontação identitária, onde qualquer posicionamento pode ser defendido e/ ou contestado, seria o espaço mais apropriado possível na atualidade para as permanentes experiências de construções e reconstruções do eu contemporâneo. Esses exercícios acabam por potencializar, em função do meio, atitudes reflexivas que tendem para arranjos identitários conjuntivos ("idiosinscréticos") e permanentemente provisórios. Segundo Luis Baggioline:

O nomadismo da rede e o modo de construir subjetividades no ciberespaço, se parecem mais a uma identidade baseada na 
possibilidade, no poder ser, que na diferença e no dever ser. A "construção de si" deixa de ser opositiva e disjuntiva (este ou aquele), e se funda nas possíveis conjunções (este e aquele), o que permite a constituição de identidades simultâneas, em contínuo movimento de reconstrução (Baggiolini, 1997).

É preciso lembrar, contudo, que um território com essas características favorece muito mais os cotejamentos identitários individuais do que as formulações identitárias mais tradicionais e sancionadas por consensos coletivamente institucionalizados. O ciberespaço, paraíso da permanente reformulação identitária individual, seria, assim, lugar fecundo para processos destradicionalizantes e desinstitucionalizantes como aqueles que assistimos no global mercado religioso dos dias atuais.

\section{As afinidades entre o ciberespaço e a religiosidade nova-erizada de Oprah e Tolle}

Feitas essas necessárias ponderações pode-se agora passar à análise do episódio do webinar de Oprah e Tolle relatado no início deste texto. É oportuno, então, indagar pelas razões do sucesso deste "ciberevento". A questão inicial é: quais os fatores que contribuíram para o surpreendente (tomando os padrões ciberespaciais) afluxo de cerca de dois milhões de internautas que o assistiu?

Cabe, primeiramente, levantar algumas hipóteses que conduzam a se considerar o sucesso do evento como decorrente de razões que extrapolam a sua natureza ciberespacial. Pode-se argumentar que, por se tratar de uma grande celebridade midiática no mundo offline, Oprah teria sido o fator atraente a inflacionar a audiência do webinar. Outrossim, se poderia argumentar que por se tratar de um webinar o evento guardou maior correspondência com as lógicas dos MCM do que com aquelas que caracterizam a CMC. Oprah estaria a realizar no ciberespaço aquilo que já vem realizando na TV e, assim, não haveria nada de essencialmente ciberespacial neste evento religioso.

Como contraponto a essas ponderações, pode-se argumentar que, até o momento, não se tem conhecimento de casos de celebridades midiáticas do mundo offline que tenham conseguido, utilizando-se de recursos disponibilizados pela internet, produzir nesse ambiente eventos tão bem sucedidos como esse de exposição pública massiva. Pode-se citar, como exemplo, o fracasso das tentativas do celebre padre Rossi no uso dessa mídia no Brasil. Suas missas e cantorias, quando transmitidas via web, só costumam atrair a atenção de uns poucos curiosos.

Também, como contestação a essas mesmas ponderações é oportuno lembrar que Oprah só é uma celebridade mediática nos EUA e a audiência 
a seu webinar chegou a ser composta por pessoas localizadas em outros 138 países. Além disso, o nível de interatividade emissores-receptores e de discussão generalizada provocado pelo evento em vários quadrantes dos ciberespaço pouco ou nada corresponde àquilo que ocorre em eventos massmediatizados.

Parece-nos muito mais crível que o sucesso deste ciberevento se deveu ao fato de seu público ser composto por indivíduos com um perfil de atitude religiosa afinada às tendências nova-erizantes da religiosidade contemporânea. Isso só pode ter ocorrido, em grande parte, por afinidade da assistência com as trajetórias biográficas da dupla Oprah e Tolle. Eles, cada um a sua maneira, não deixam de encarnar dois dos principais modelos possíveis de trajetórias novaerizantes. Tolle, o guru ocidental que, tendo vivido experiências excêntricas ao longo de sua vida, desde cedo se inclinou para modalidades destradicionalizadas e desinstitucionalizadas de religiosidade alternativa, solidificando, por fim, um carisma de mestre New Age. Oprah, a neófita que, oriunda de uma tradição religiosa tendente ao antissincretismo e solidamente institucionalizada, aventura-se a realizar exercícios heterodoxos de reflexividade e construção idiossincrética de novas, e sempre provisórias, posturas religiosas. Ambos, portanto, só poderiam atrair, em sua maioria, as massas heteróclitas de adeptos da Nova Era que ali estavam, não como receptores passivos de mensagens mass-mediatizadas unidirecionais, mas, sim, como ativos interpeladores a indagar sobre aqueles pontos que, idiossincrasicamente, lhes interessaram. A polifonia discursiva decorrente disso, embora contida num primeiro momento pelo formato webinar adotado pelo evento, logo irrompeu num fluxo torrencial de negociações reflexivas a cerca dos significados e impactos dos discursos proferidos.

Se assim o foi, fortalecem-se nossas convicções de que fazem melhor uso da internet aquelas religiões e/ou religiosidades que dependem muito mais da ação autônoma de seus adeptos do que de ações institucionais centralizadoras. E isso não vale somente para as modalidades religiosas indiscutivelmente integrantes do movimento Nova Era. Vale também para religiões tradicionais que sofrem processos nova-erizantes. Um grande número de evangélicos brasileiros, por exemplo, embora constrangidos pela ortodoxia das tradições doutrinarias que professam - a transigência idiossincrética deles é muito limitada se comparado a outras modalidades religiosas -, atiram-se militantemente aos jogos de afirmação e confrontação identitária celebrados no ciberespaço. Não deixam, por essa razão, de ensaiarem posturas reflexivas e nova-erizantes e beneficiarem-se destas para defesa e difusão das instituições tradicionais a que se encontram vinculados. 
Vemos portanto algo como uma "afinidade eletiva" entre essa atitude autônoma reflexiva, destradicionalizante, que tem sua expressão modelar na Nova Era e nas modalidades religiosas que sofrem processos de nova-erização, e algumas das lógicas que imperam do ciberespaço particularmente aquelas que o tornam um espécie de tecnologia do eu.

Por "afinidade eletiva", assumimos as definições de Michel Löwy, que conceitualmente as depurou dos usos do termo feitos por autores como Goethe, Weber e outros. Segundo este autor, por "afinidade eletiva" devemos entender "um tipo muito particular de relação dialética que se estabelece entre duas configurações sociais ou culturais não redutível à determinação causal direta ou 'influência' no sentido tradicional". Ela ocorre a partir "de um movimento de convergência, de atração recíproca, de confluência ativa, de combinação capaz de chegar até a fusão" e sua percepção se dá "a partir de uma certa analogia estrutural" (Löwy, 1998, p. 23). Para o autor, tratase um "conceito que nos permite justificar processos de interação que não dependem nem da causalidade direta, nem da relação 'expressiva' entre forma e conteúdo (por exemplo, a forma religiosa como 'expressão' de um conteúdo político ou social)". A "afinidade eletiva" não ocorre "no vazio ou na placidez da espiritualidade pura: ela é favorecida (ou desfavorecida) por condições históricas ou sociais" (Ibidem, p. 18).

Pensamos que, da mesma forma que as religiões institucionalizadas, "de igreja", souberam no passado e sabem no presente beneficiar-se dos meios de comunicação massivos (veículos impressos, rádio e TV), as religiões e religiosidades desinstitucionalizadas da atualidade (nova-erizadas, idiossincréticas, reflexivas, etc.) tendem cada vez mais a ter na comunicação mediada por computador seu principal veículo comunicacional. Essa afinidade eletiva entre as lógicas comunicacionais que operam no ciberespaço e as religiões e religiosidades desinstitucionalizadas de que falamos é, evidentemente, favorecida pelas condições históricas e sociais da atualidade que promovem tanto a autonomização crescente, e até exacerbada, diriam alguns, do eu contemporâneo, como a otimização maquínica das estratégias de pertencimento social, de posicionamento identitário, de construção de trajetos subjetivos do eu, etc. que se assiste com a emergência do ciberespaço. Tratamse, pois, de processos afins que mantêm entre si uma visível "confluência ativa" pois, da mesma forma que a religião e religiosidade de que falamos tira proveito da otimização maquínica promovida pelo ciberespaço, também esse vê suas potencialidades serem bem exploradas pelos usos reflexivistas que agentes nova-erizados dele fazem. Isso, em parte, explica o sucesso do webinar de Oprah e Tolle. Ali estava, de forma massiva, todo um exército 
heteróclito de sujeitos nova-erizados que, muito provavelmente, foram atraídos não só pelos apelos reflexivistas emanados dos discursos da dupla, mas pela possibilidade de exercitar autonomamente o pertencimento a uma polifonia só possível pelas otimizações maquínicas possibilitadas pelo ciberespaço. Eletivamente afinados, ali estavam a Nova Era e o ciberespaço a celebrar, como nunca antes se havia visto, uma irresistível atração recíproca.

\section{Referências}

BAGGIOLINI, Luis. Desterritorialización y globalización: la constitución de las nuevas redes virtuales. Trabalho apresentado nas "III Jornadas Nacionales de Investigadores en Comunicación”, Mendoza, Argentina, 1997.

BLOOM, Harold. Presságios do milênio: anjos, sonhos e imortalidade. Rio de Janeiro: Objetiva, 1996.

BRIGGS, Asa; BURKE, Peter. Uma história social da mídia: de Gutenberg à internet. Rio de Janeiro: Zahar, 2004.

CAMPBELL, Colin. A orientalização do Ocidente: reflexões sobre uma nova teodicéia para um novo milênio. Religião e Sociedade. v. 18, n. 1, p. 5-22, 1997.

D'ANDREA, Anthony A. F. O self perfeito e a nova era: individualismo e reflexividade em religiosidades pós-tradicionais. Dissertação de Mestrado. PPG em Sociologia do Iuperj. Rio de Janeiro, 1996.

DURKHEIM, Émile. As formas elementares da vida religiosa: o sistema totêmico na Austrália. São Paulo: Ed. Paulinas, 1989.

EDDY, Mary Baker. Ciência e saúde com a chave das escrituras. Boston: First Church of Christ Scientist, 1995.

FRY, Peter. Religião e destradicionalização na África austral. Trabalho apresentado nas VIII Jornadas sobre Alternativas Religiosas na América Latina. São Paulo, 1998.

GURTWIRTH, Jacques. L'eglise életronique: la saga des télévangélistes. Paris: Bayard Éditions, 1998.

HANEGRAAFF, Hank. Cristianismo em crise. Rio de Janeiro: Casa Publicadora das Assembleias de Deus, 1996.

HILLIS, W. Daniel. Depoimento a John Brockman. In: BROCKMAN, John. Digerati: encontros com a elite digital. Rio de Janeiro: Campus, 1997, p. 107-114.

JUNGBLUT, Airton L. Os evangélicos brasileiros e a colonização da internet. Ciencias Sociales y Religión/Ciências Sociais e Religião, Porto Alegre, n. 4, p. 149-166, 2002

. O Evangelho New Age: sobre a gnose evangélica no Brasil. Civitas, v. 6, p. 101-121, 2006.

. The use of the internet for religious groups in Brazil. Trabalho apresentado no First ISA Forum of Sociology. Barcelona, 2008. 
LÖWY, Michael. Redenção e utopia: o judaísmo libertário na Europa Central. São Paulo: Companhia das Letras, 1998.

SANCHIS, Pierre. O campo religioso contemporâneo no Brasil. In: ORO, A. P.; STEIL, C. A. (Org.) Globalização e religião. Petrópolis: Vozes, 1997, p. 103-116.

TAYLOR, LaTonya. The church of O. Christianity Today. April 1, 2002,

TOLLE, Eckhart. The power of now: a guide to spiritual enlightenment. California: New World Library, 1999.

Un nuevo mundo, ahora. Barcelona: Litografia Rosés, 2007.

VELHO, Otávio. Globalização: antropologia e religião. In: ORO, A. P.; STEIL, C. A. (Orgs.) Globalização e religião. Petrópolis: Vozes, 1997, p. 43-62.

Recebido em: 30 abr. 2009 Aprovado em: 26 ago. 2009 